\title{
The Challenge Of Botsourcing
}

Richard Vedder, University of North Texas, USA

Carl S. Guynes, University of North Texas, USA

\begin{abstract}
Botsourcing is the augmentation or replacement of human jobs by robots or other computing systems. This practice is growing in popularity for reasons both economic and technical. Botsourcing will seriously challenge the human workforce, and in some cases humans will find themselves working alongside robots or other "intelligent' computer systems. In other cases, botsourcing will eliminate jobs and will force impacted humans to retrain. This paper discusses the nature and appeal of botsourcing, as well as the challenge to human employment.
\end{abstract}

Keywords: Botsourcing; Offshoring; IT Workers; Man-Machine Systems; Unemployment; Retraining

\section{INTRODUCTION}

(.) ver the last decade and more, the United States and other developed countries have experienced a decline in the economic well-being of an increasingly large portion of their citizens, leading to unprecedented disparities in wealth. One of the factors contributing to this situation is the growing use in the workplace of robots and other advanced computer systems (Brynjolfsson and McAfee, 2014).

To label this development using the word "computerization" is inadequate, as the term does not bring to mind an application space far beyond that of traditional office or factory systems. Botsourcing has been defined as "the use of robots or robotic technology to replace human workers". Although certainly a better term, this process is actually more nuanced and extensive. (Waytz and Norton, 2014).

Advances in software automation such as robotic process automation, AI and cognitive technology are triggering a public debate in America and the UK. Repetitive and mundane jobs can be at risk as robots and super computers are better suited to perform more productively precision and routine tasks. (Hearnden, 2014)

Over the past 10-15 years there has been an explosion in the capabilities of both robots and computing systems in general. These advances allow robots and other computer systems to assist humans in their work, as well as replace them in some instances (Brynjolfsson and McAfee, 2014). In this paper the authors will use the term botsourcing, but define it as "the augmentation or replacement of human workers by robots or other computing systems."

\section{THE IMPORTANCE OF BOTSOURCING}

The foundation for the botsourcing phenomenon lies in the explosion of IT products and services brought about by enormous improvements in IT itself (ex., processing power, sensors). Thomas Friedman (2011) provides an example:

I wrote about the connected world in 2004, arguing that the world had gotten "flat." When I made that argument, though, Facebook barely existed - and Twitter, cloud computing, iPhones, LinkedIn, iPads, the "applications" industry and Skype had either not been invented or were in their infancy.... In the last decade, we have gone from a connected world (thanks to the end of the cold war, globalization and the Internet) to a hyper connected world (thanks to those same forces expanding even faster).

As an example of the many authors who have written about this phenomenon, Brynjolfsson and McAfee (2014) identify five technologies experiencing recent and rapid advancement: Pattern recognition (ex., autonomous 
vehicles), natural language processing (ex., Siri), translation utilities (ex., Google Translate), automated learning (ex IBM's Watson), and robotics (ex., Baxter).

One of the results of this technological explosion is the availability of enormous quantities of digitized data on an ever-growing range of subjects. Analysis of this steadily-increasing amount of data, using the techniques of data mining, exposes patterns or structures of knowledge, performance, or behavior. One important use of these discoveries is creating better algorithms for robots and other computing systems (ex., reviewing tens of thousands of treatment records for cancer patients to identify the best approach for a specific cancer patient). This ability to provide more comprehensive analysis of historical cases is extremely powerful; it enables development of robotic or computer applications for problems earlier thought to be too complex for machines (Frey and Osborne, 2013; Manyika et al, 2013).

As North American manufacturers face ever-growing challenges to remain competitive in the global marketplace, they frequently look to overseas sources as a way to cut costs. Although the appeal of low-cost labor may lead a company to implement this course, and it sometimes makes sense, there are numerous other factors to consider. Among them are factory efficiency, inventory requirements, the strength of the U.S. labor force, government support and stability, supply chain strength, and intellectual property protection (Schneider, 2014). Rethink Robotics says that moving manufacturing operations overseas is not the only route to remaining competitive. By focusing on innovation and recognizing that automation and robotics are often more cost-effective and profitable alternatives, North American manufacturing companies can achieve cost-savings while improving quality and control. The result of automating is lower labor costs, lower transportation costs, and shorter and more responsive supply chains. (Schneider, 2014).

For developed nations, these advancements have lowered costs for making things and doing business in general (Brynjolfsson and McAfee, 2014). In the United States, profitability is even more favorable because fracking technologies have reduced energy costs (compared with Europe, for example). When the rising wages in developing nations and the significant risks associated with a global supply chain are added to the mix, botsourcing becomes very attractive. Indeed, the economic strengths of botsourcing can have a negative impact on offshoring, as jobs return from overseas. For example, botsourcing is considered a major threat to India's multi-billion-dollar IT industry (Lewis, 2014).

\section{CHALLENGES FOR COMPANIES}

As botsourcing grows, one of the major decisions companies are going to have to make is whether to adopt this practice in-house or outsource. One argument in favor of an in-house approach is that the new technologies are much more generic in their range of applications than in the past. For example, moving beyond chess and Jeopardy! IBM touts Watson for applications in healthcare, finance, retail, and other sectors (IBM, 2014). Rethink Robotics provides a different example with Baxter, an inexpensive (c. \$20,000) robot that is easy to train and does not take up a lot of space (Guizzo and Ackerman, 2012).

From a psychological standpoint, what human-machine interfaces will be most appropriate? From an organizational standpoint, how will botsourcing change business practices or industry and government standards? The State of California has already passed legislation to regulate driverless cars (Iozzio, 2014). Again, how will the insurance industry react to robotic care of infirm or elderly patients? In turn, how will those changes shape future healthcare management structure and responsibilities?

From an HR standpoint, what sort of transition policy should a botsourcing company adopt for affected employees? Will botsourcing cause changes in the physical structure of a company, similar to what happened in factory design when electricity replaced steam power (Brynjolfsson and McAfee, 2014)? 


\section{WHAT IS THE HUMAN LABOR FORCE GOING TO DO?}

Oxford University researchers estimate that $47 \%$ of total US jobs are vulnerable to computerization over the next 10-20 years (Frey and Osborne, 2013). Both the Oxford study and Brynjolfsson and McAfee (2014) agree that the jobs most at risk for botsourcing are those characterized by well-defined problem solving. Per se, this is not new. What is new, as these authors stress, is the broadened scope of what now constitutes a "well-defined problem" courtesy of data mining and other recent computing and sensory advances. For example, 10 years ago autonomous vehicles performed very poorly. Now the McKinsey Global Institute forecasts self-driving taxis, buses, and trucks to enter the marketplace by 2025, if not sooner (Manyika et al, 2013; Brynjolfsson and McAfee, 2014). Serious unemployment within the transportation sector is a likely outcome.

Another possibility would be for displaced workers to become micro-entrepreneurs offering customized services (Redman, 2014). They would do this by advertising their skills on the Internet (ex., at Fiverr.com or freelancer.com) and combining their skill sets with others to engage in contract work. Of course this assumes that the displaced worker can offer still-marketable skills and has the business knowledge to be a successful entrepreneur. Another downside is that micro-entrepreneurs may well have to complete a lot of work to earn a decent living, since the average reported bids for many projects can be in the hundreds of dollars (Friedman, 2011).

Alluded to earlier, another response would be to seek retraining. But this solution is not as straight-forward as it appears to be. At the present time, "going back to school" is an expensive proposition, especially for a displaced worker. Moreover, there is the very real question of what jobs or disciplines are suitable goals for retraining. The speeding pace of technological change makes this choice not only hard to determine but also a moving target. Although the 2013 Oxford study rated 70 occupations for their vulnerability or resistance to being computerized in the relatively near future, the authors recognized that their assessments could definitely be challenged by unforeseen technological developments.

Finally, another response by displaced workers could be a $21^{\text {st }}$-century form of luddism. While physical attacks on the displacing technologies would be difficult because of the diffused nature of most IT, demonstrations, strikes, and other forms of protest or social pressure could delay introduction of botsourcing in some cases.

\section{FINAL REMARKS}

There are a number of possible ways that the impacted human workforce could adapt or respond to botsourcing. One option would be to exploit the synergy possible between human and machine in many occupations, with each component doing what it does best. An example would be a computerized legal assistant for a human attorney. Such hybrid botsourcing makes sense for several reasons. It could improve the level of human trust in the computer system's performance if significant human involvement remains. Also, even with the use of data mining and related techniques, it may well take time to develop problem-solving algorithms in many areas, thus requiring continued human involvement. Finally, this practice might buy time for human workers to retrain.

\section{AUTHOR BIOGRAPHIES}

Richard G. Vedder is a Professor of Information Systems at the University of North Texas. He received his Ph.D. from the University of Arizona. His research interests include multimedia systems, knowledge-based systems, impact of new technologies and competitive intelligence. He has published articles in Decision Sciences, Communications of the ACM, Computers and Society, IEEE Transactions on Systems, Man and Cybernetics, Expert Systems, and Journal of Information Systems Management. (Contact Author) Email: vedder@unt.edu

C. Stephen Guynes is a Regents Professor of Information Systems at the University of North Texas. He received a doctorate in quantitative analysis from Texas Tech University. Dr. Guynes' areas of specialization are client/server computing, end-user computing, data administration, and information resource management. His most recent research efforts have been directed in the areas of client/server computing and data administration. Some of the journals in which Dr. Guynes has published include Communications of the ACM, Information \& Management, The Journal of Information Systems Management, Journal of Accountancy, Journal of Systems Management, The 
Journal of Database Management, The CPA Journal, The Journal of Computer Information Systems, Information Strategy, Computers and Security, and Computers and Society

\section{REFERENCES}

Brynjolfsson, E. and McAfee, A. The Second Machine Age: Work, Progress, and Prosperity in a Time of Brilliant Technologies (NY: Norton, 2014).

Frey, C. and Osborne, M., The Future of Employment: How Susceptible Are Jobs to Computerisation? Oxford Martin School working paper (September 17, 2013).

Friedman, T. "How Did the Robot End Up With My Job?" The New York Times (1 October 2011), p. SR11.

Guizzo, E. and Ackerman, E. "How Rethink Robotics Built Its New Baxter Robot Worker" IEEE Spectrum (October 2012), retrieved from http://spectrum.ieee.org/magazine/2012/October

Hearndon, Stephen. "Botsourcing and the Productivity Race" (May 2014), WWW. TechUK.org .

IBM. "Implement Watson" (August 2014), retrieved from http://www.ibm.com/smarterplanet/us/en/ibmwatson/implementwatson.html

Iozzio, Corinne. "Street-Legal Robots." Scientific American 311.2 (August 2014), 20.

Lewis, C. "Robots Are Starting to Make Offshoring Less Attractive" (12 May 2014) retrieved from http://blogs.hbr.org/2014/05/robots-are-starting-to-make-offshoring-less-attractive

Manyika, James Chui, Michael Bughin, Jacques Dobbs, Richard Bisson, Peter and Marrs, Alex. Disruptive technologies: Advances that will transform life, business, and the global economy. McKinsey Global Institute Report, May 2013.

Redman, D. "When Worlds Collide: Entrepreneurship and Botsourcing" (21 Feb. 2014) retrieved from http://rock9digital.com/affiliate-marketing/entrepreneurs-botsourcing

Schneider, Rick. "Robotics and Automation Can Save Your Factory" (June 2014), www.lincolnelectric.com.

Waytz, A. and Norton, M. "Botsourcing and Outsourcing: Robot, British, Chinese, and German Workers Are for Thinking—Not Feeling—Jobs" Emotion 14, no. 2 (April 2014): 434-444. 